\title{
O Abuso de Medicamentos Psicotrópicos na Contemporaneidade
}

Resumo: o artigo propõe uma análise crítica do fenômeno do abuso de medicamentos psicotrópicos na atualidade. A base teórica é a psicanálise. A argumentação parte da discussão da subjetividade contemporânea, resgatando o conceito de mal-estar na civilização em Freud, para elucidar algumas das causas e dos efeitos desse fato atual.

Palavras-Chave: Medicamento psicotrópico, subjetividade, cultura.

\section{Marta Regueira Fonseca Pelegrini}

Psicóloga formada na Universidade de Brasilia Pós-graduação: Especialização em Teoria Psicanalítica Mestranda em Psicologia Clínica na Universidade de Brasilia Trabalha em consultório particular e na Clínica

Renascer para dependentes de drogas

Formação em Psicanálise pelo Percurso Psicanalítico

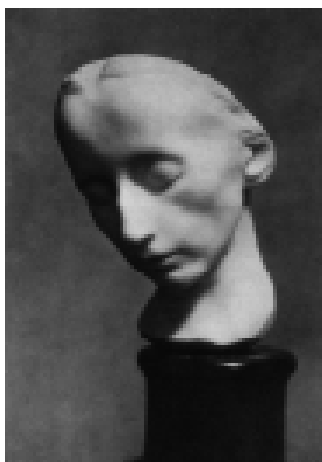

Abstract: The article propose a critical analyse about the abuse of psychotropy medicines, usuing the theory of psychoanalyses and the discussion about the subjectivite process.

Key-Words: subjectivity, culture.

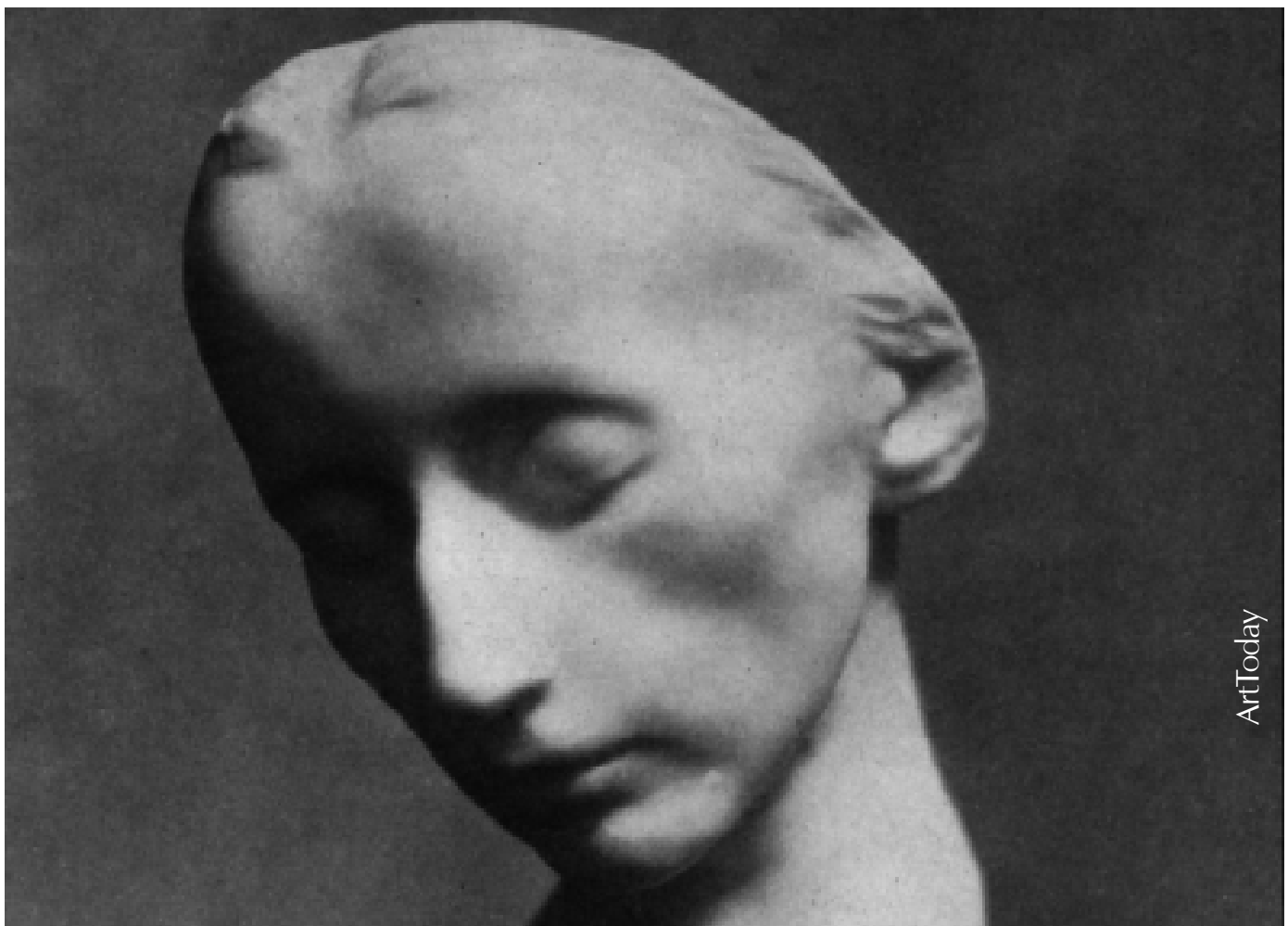

A questão do inegável abuso que hoje se verifica no consumo de medicamentos psicotrópicos está a demandar séria reflexão. É fato consabido que, ao grave problema da automedicação, acrescese uma prescrição excessiva, em especial dos ansiolíticos e dos antidepressivos, por parte dos médicos. O exame de uma possível interrelação entre esse fenômeno e determinados aspectos de nossa cultura é o objetivo a que nos propomos neste artigo. Nessa busca, tomaremos o caminho
Segundo Birman (1999), a tendência moderna de construção da subjetividade em que o Eu se encontra situado em posição privilegiada leva a um autocentramento do sujeito. A subjetividade, no início da modernidade, tinha, como eixos constitutivos, as noções de interioridade e de introspecção. Sua moral, seus sentimentos e vivências íntimas definiam o homem. Atualmente, a exterioridade é o valor. Os signos externos, como os bens de consumo, são os delimitadores do que cada um é. Assim, a subjetividade assume uma configuração decididamente estetizante, em 
que o olhar do outro passa a ocupar uma posição estratégica na economia psíquica do sujeito. Os destinos do desejo assumem uma direção marcadamente exibicionista e autocentrada. Há, então, uma auto-exaltação desmesurada da individualidade num mundo de espetacular fosforescência. O que se procura é o engrandecimento da própria imagem.

Maia e Albuquerque (2000) definem a sociedade contemporânea como a da cultura da imagem, em que o instantâneo e a busca pela satisfação imediata e contínua dos desejos são os valores predominantes. O imediato é valor que permeia vários aspectos da cultura e constitui qualidade essencial a qualquer bem a ser consumido. Os sofrimentos, como a ansiedade, a angústia e a tristeza, que sinalizam circunstâncias e situações humanas e para elas preparam o homem, são aplacados pela medicação. "Busca-se permanecer no estado de prazer e alegria, ao preço de se eliminar parte da experiência humana. É como se, socialmente, não se reconhecessem mais a dor e a frustração como constitutivos do percurso rumo aos ideais de prazer e alegria. Dor e frustração deixam de ser indicadores dos limites inerentes à experiência daquele sujeito singular. Ou seja, veicula-se a idéia de que essa imagem ideal de pleno prazer está disponível para todos a mínimo esforço e que a não concretização desse modelo decorre de problemas particulares daquele sujeito" (Maia e Albuquerque, 2000, pg.83).

A temporalidade já não é a mesma. Predomina agora, sob a ordem do imediato, a exigência de se alcançar, ontem, o modelo ideal. Com essa urgência, o processo, antes de constituir-se em trajetória para uma meta, é vivido como obstáculo a ser superado. Experimenta-se, como da ordem do insuportável, o adiamento da satisfação que seria alcançada ao serem atingidos os ideais. Assim, todos os meios para alcançar resultados favoráveis - e imediatos - tornam-se válidos.

Impera, hoje, o apelo emblemático ao prazer. Um prazer que não se resume apenas à ausência de sofrimento, mas que há de ser intenso, imediato, não-negociável. O imperativo é: "quero agora, quero muito, quero tudo, e sempre". O discurso social idolatra a posição de plenitude alcançada sem muito esforço. É a tentativa de abolição da falta, do vazio e de qualquer insatisfação. Já não se valoriza a satisfação "pequena", "ordinária", "comum"; o máximo de prazer - e que seja imediato - é o que se quer.

Estar sempre bem, de bom humor são os "estados de espírito" que o discurso atual valoriza. O desejo visa, sempre, à imediata satisfação, já que seu adiamento apresenta-se intolerável. Não há abertura para escolhas, e a negociação entre perdas e ganhos inexiste: "quer-se tudo, e agora!"

A publicidade é, a esse respeito, paradigmática: traz, ao consumidor, promessas de felicidade e de satisfação absolutas. Nas imagens veiculadas, há sempre um sorriso estampado nos rostos, de plastificada beleza, que vende a proposta de viver um prazer contagiante.

Segundo Birman (1999), a psicopatologia da "pósmodernidade" caracteriza-se por um funcionamento psíquico de fracasso na realização e na glorificação do Eu e na estetização da existência, ou seja, o fracasso em participar da cultura do narcisismo e do espetáculo. Daí a depressão, a síndrome do pânico, a toxicomania... Deprimido ou em pânico, o sujeito não mais está apto a exercer o fascínio da estetização da existência e passa a ser considerado um perdedor, segundo os valores axiais dessa visão de mundo. Surge, então, a droga, como solução viável. Com seu uso sistemático, busca-se desesperadamente o acesso à majestade da cultura do espetáculo e ao mundo da performance. Há que se glorificar o Eu, mesmo que, para tanto, os caminhos sejam os bioquímicos e os farmacológicos.

Penetra-se, então, no universo das drogas: das drogas ilícitas ou dos medicamentos prescritos pela Psiquiatria; participantes, tanto uma quanto o outro, do mesmo universo, na medida em que visam a tornar o Eu apto ao exercício da cidadania do espetáculo. Enquanto as chamadas drogas pesadas têm por fim a exaltação nirvânica do $E u$, inebriando a individualidade para o desempenho na cultura da imagem, as drogas ditas medicinais pretendem, ao conter angústias e sentimento, capacitar o indivíduo para as mazelas do narcisismo.

Em meio a essas caraterísticas da contemporaneidade, a Psiquiatria ganhou, há apenas algumas décadas, com o desenvolvimento da Psicofarmacologia e da Neurologia, estatuto de ciência. Também deixou de ser uma disciplina voltada exclusivamente para o tratamento da loucura e passou a tratar dos pequenos "malestares" cotidianos e da "dor-de-existir", com um conseqüente aumento da medicalização das dificuldades psíquicas e emocionais. Para cada mal, a Psiquiatria passou a ter um remédio.

Como movimento característico do último século, Calligaris (2000) aponta o buscar maneiras de medicar nossos "nervos". Aos opiáceos sucedeu a cocaína, depois foi a vez dos barbitúricos, logo vieram as anfetaminas e, enfim, chegaram os ansiolíticos. Nessa sucessão, observa-se uma espécie de alternância: a uma substância a ser 
consumida para "subir" segue-se outra destinada a "descer". Inicialmente, respostas a necessidades médicas logo são adotadas como corretivo da banalidade cotidiana. São substâncias que modificam a existência do homem e sua presença no mundo. Há, portanto, no seu uso, para além de um propósito terapêutico, um intento hedonista, visto que urge seja o sofrimento banido de qualquer maneira.

Ainda segundo Calligaris, o sucesso dos antidepressivos na década de 1990 não foi fruto de nenhum triunfo da ciência. Antes, é a conseqüência da nova atitude cultural: queremos que nosso sofrimento psíquico deixe de ser um drama subjetivo e passe a ser visto e vivido como um problema médico. Aos antidepressivos é pedido que tratem nosso mal-estar como uma disfunção do corpo, posição que leva a um assujeitamento, ou seja, o sujeito se retira de seu sofrimento, que passa a ser um mero distúrbio neurofisiológico. Instala-se a passividade: a pessoa não se vê como protagonista do seu adoecimento. Há como que a desistência da dura tarefa de mudar.

\section{É a modernidade que vê na melancolia um problema, \\ possivelmente por ser uma ameaça à inserção social do indivíduo e à capacidade produtiva.}

1 Não é à toa que a cocaína se tornou a drog a dos anos oitenta, época áurea dos yuppies, do self made man $e$ do capitalismo competitivo.

Dentro desse quadro, não é de se estranhar que se tenham tornado estigmatizantes certos tipos de comportamento e de síndromes, como a depressão, por exemplo. Ela não é tolerada nem em si mesmo nem nos outros. E não é tolerada na forma como são considerados os distúrbios de humor, nos seus dois pólos: o maníaco e o depressivo. Nas sociedades competitivas, o pólo maníaco é muito mais aceito e, até mesmo, estimulado.

Entretanto, é preciso diferenciar a depressão propriamente dita (com sintomas incapacitantes e que trazem muito sofrimento) das "baixas" do humor normal da vida. Há uma banalização do seu diagnóstico e qualquer tristeza ou "baixo astral" passa a ser depressão e com necessidade de tratamento.

Ainda segundo o médico, é grande o número de pessoas que procuram o psiquiatra não porque estejam doentes, mas porque desejam mudar o seu humor, sua personalidade, seu jeito de ser. Querem fazer uma maquiagem no seu psiquismo, no seu estado de espírito. $\mathrm{O}$ bem de consumo prometido é um comportamento standard, uma alegria artificial que não dá margem a alterações de humor, que pode ser percebida ao analisar as propagandas dos laboratórios farmacêuticos onde há pessoas estonteantes de tanta alegria e vigor.

A "substância mágica" da atualidade - e autorizada - é, então, o antidepressivo, o que mostra como a depressão é o espectro da modernidade. Mas esse estado humoral nem sempre foi considerado como doença. Para os filósofos na Grécia Antiga, bastava controlá-lo. A melancolia era uma predisposição que levava a um distúrbio dos humores, um excesso do que eles chamavam de bile negra, curável por dietas e purgas. Nada de preocupante e quase sempre associado à capacidade de criação do artista, filósofo ou herói. É a modernidade que vê na melancolia um problema, possivelmente por ser uma ameaça à inserção social do indivíduo e à capacidade produtiva.

Evidentemente, quem busca em remédios uma "máscara para a alma" precisa lembrar que são paraísos artificiais, para usar uma expressão do poeta francês Baudelaire (citado por Scliar). Essas substâncias podem fazer com que o sujeito se afunde de vez, mas com prescrição médica, pois não analisa na profundidade o que se passa com o sujeito, ou seja, não elimina as causas de seu sofrimento. porque, sendo os indivíduos, em nossa sociedade, constantemente instados a tomar decisões, a mover-se, a fazer coisas, a agir, quem se isola e se recolhe a um canto é criticado, desprezado. Impossível negar a determinação social existente
Bogochvol (1997) também traz uma reflexão crítica dessa situação. Explica que existe um novo paradigma e uma nova ordem na Psiquiatria com o desenvolvimento das neurociências. $O$ campo psiquiátrico teria encontrado, enfim, com as neurociências, suas bases seguras, biológicas e mais que isto, teria se revelado como intrinsecamente biológico. Para o autor, estamos na Era do Prozac, no Reino dos Neurotransmissores, 
na Década do Cérebro... A Psiquiatria Biológica, a partir das Neurociências, propõe modelos biológicos para explicar uma gama extensa de fenômenos psiquiátricos e psicológicos: angústia, fobias, obsessões, depressão, esquizofrenia, farmacodependências, personalidades, delírios, inteligência, afetos, humor... O problema é que, em geral, tomam esses fenômenos redutíveis inteiramente à biologia. O fenômeno psicopatológico é concebido como produto de um distúrbio neurofisiológico tratável farmacologicamente. Nessa concepção, o sintoma expressa no plano psíquico aquilo que é primariamente um transtorno da neurotransmissão cerebral. Entre o psíquico e o psicopatológico haveria uma ruptura que é função de diferenças estritamente biológicas. Assim, nessa linha de pensamento, o biológico transforma o psíquico em psicopatológico, visto que o psíquico é tido como efeito do orgânico.

Dessa forma, o tratamento se resume em uma intervenção no corpo, para uma retomada do equilibro neurológico. Não se pretende mais, no discurso médico, a cura (que atuaria nas causas), mas a regulação do mal-estar: apenas uma eliminação dos sintomas.

Com a crescente melhora dos resultados terapêuticos obtidos pelos tratamentos medicamentosos, reduzindo drasticamente o tempo e o gasto econômico necessários para se obter um alívio do sofrimento e das limitações impostas pela dor mental, a Psicanálise (ou qualquer proposta de psicoterapia) passou a verse numa posição desconfortável quanto à justificativa de suas propostas clínicas, num mundo onde cada vez mais são valorizadas a eficiência, a rapidez e a garantia.

Freud pode nos ajudar a entender essa situação em questão. No texto O Mal-estar na Civilização(1930[1929]), ele traz a tese de que há um mal-estar inerente à constituição da cultura que seria resultado do antagonismo entre as exigências da pulsão e as restrições que a civilização impõe à sua satisfação. Nesse conflito se encontra o homem marcado pela insatisfação e pela infelicidade em uma busca infindável e infantil da felicidade perdida e jamais reencontrada.

Ainda segundo o autor, procuramos medidas paliativas para nos aliviar desses sofrimentos e decepções da vida, e entre esses paliativos existem basicamente dois tipos: satisfações substitutivas que diminuem o "sofrer" e substâncias tóxicas que nos tornam insensíveis a ele. Essa busca se embasa no fato de o "sonho" do homem ser a conquista da felicidade que pode ser alcançada pela busca de sensações de prazer ou pela diminuição do sofrimento. Nesse processo está o princípio de prazer atuando.
Entretanto, o homem procura formas de resolver o impasse colocado na constituição da civilização e na entrada na cultura. Nesse impasse, surge a tarefa de se passar do funcionamento no princípio do prazer, exclusivamente, para o princípio da realidade, onde o desejo precisa ser negociado, muitas vezes adiado. O imperativo do gozar abre espaço para formas socializadas de obtenção de prazer. Gradativamente, haverá a passagem do prazer imediato voltado para o auto-erotismo, lugar narcísico do eu ideal, para formas postergadas de prazer - ou formas de prazer mediado com o desenvolvimento do ideal do eu.

Outra forma de explicitar esse processo é lembrar que, na infância, o bebê alucina diante da insatisfação de seu desejo, como quando da ausência do peito. Com a constituição do aparelho psíquico, começa a negociação do desejo com a realidade, a possibilidade de adiamento ou mesmo de se lidar com a falta do objeto.

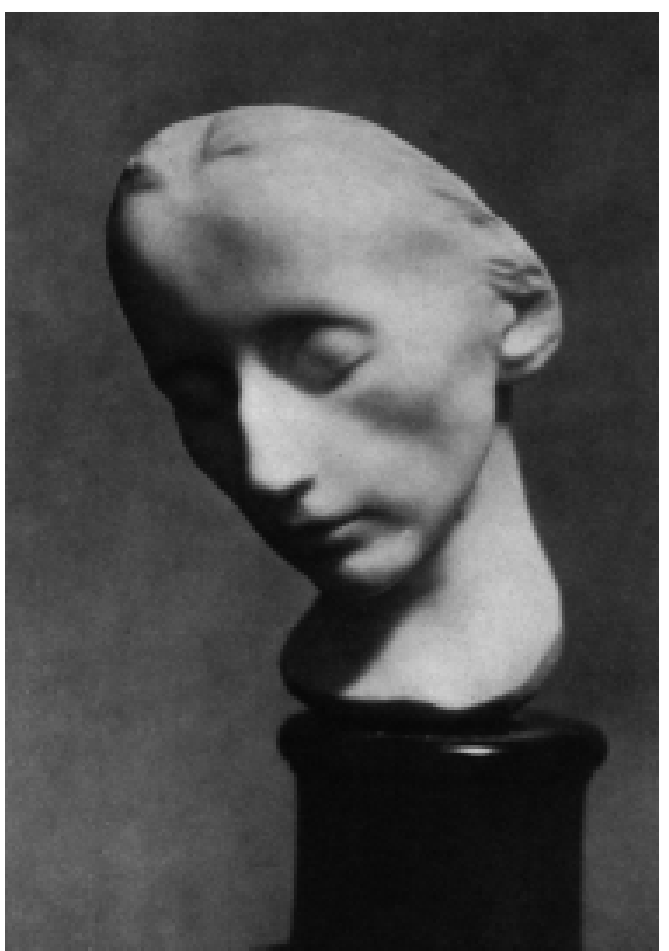

Nossa hipótese é que, enquanto cultura, estamos a cultivar essa primeira posição marcada pelo funcionamento de princípio do prazer e a evitar o caminho de constituição do sujeito faltante regido pelo princípio da realidade. Nesse sentido, o uso de substâncias psicoativas que alteram a percepção, os sentidos e o humor tem a função de permitir essa alucinação do objeto e da satisfação. Assim, usando drogas (lícitas ou ilícitas) torna-se possível atingir o ideal prometido pelo discurso corrente.

Nossa hipótese é que, enquanto cultura, estamos a cultivar essa primeira posição marcada pelo funcionamento de princípio do prazer e a evitar o caminho de constituição do sujeito faltante regido pelo princípio da realidade. 
Martins (1995) vai numa direção que corrobora a discussão. Afirma que quando dizemos que o clima cultural ocidental parece dominado pelo espectro da melancolia é justamente por ser perceptível a criação de um mundo onde a alegria, a agitação, a alta produtividade, a fugacidade, o gozo rápido e múltiplo parece dominar as concepções mais comuns de felicidade. Elembra que essa insistência no triunfo só pode ser prenúncio da possibilidade de dor. A exaltação (do humor, do consumo, do prazer) pode ser vista como uma espécie de defesa contra uma possível dor que já começa a se apresentar.

Fica claro o movimento de evitação da dor e a posição de não se falar ou se perguntar sobre ela ou sobre suas causas. A questão é se essa evitação é resultante desse discurso do prazer ou de uma impossibilidade mesmo, que impediria qualquer outra "solução" que não uma evitação ou uma defesa maníaca. Essa impossibilidade pode ser vista como uma falta de recursos psíquicos defensivos para elaborar o que causa essa dor, como uma dificuldade na simbolização, ou um encurtamento do espaço psíquico que dificulta a elaboração das experiências de perda e dor.

Podemos nos indagar se não seria essa dificuldade de simbolização, essa redução do espaço psíquico que levaria a falhas ou mesmo à impossibilidade de se elaborar a falta primordial. Não poder simbolizar essa falta, elaborar a insatisfação que advém dela, leva a posições subjetivas marcadas pelo agir. Assim, as compulsões ou adições podem ser entendidas como respostas ao mal-estar contemporâneo, como uma tentativa de aliviar o sofrimento advindo da impossibilidade de simbolizar a castração.
O preço da civilização, retomando Freud, fica por demais oneroso, uma vez que a angústia resultante da renúncia aos desejos e da vivência da castração não simbolizada seria insuportável. Daí a necessidade de agir e da descarga em impulsos.

Precisamos retomar a idéia de que o mal-estar, definido por Freud como efeito da ausência de satisfação total ou da completude, é inerente à condição de ser humano, visto que este é um ser simbólico que saiu do registro da necessidade e entrou no do desejo (que é incompleto e sempre insatisfeito por sua natureza). O mal-estar, como resultado das negociações no processo civilizatório, como preço a pagar pela cultura, é fundante, porque funda, constitui o homem. Nesse caminho, não faz sentido tentar eliminálo, a não ser que se escolha viver na "ilha da fantasia" - propiciada pelas drogas, por exemplo, mas que não dura muito tempo.

Não se pretende aqui, com essa análise crítica, ignorar a validade da Psiquiatria e da Psicofarmacologia. Essas têm seu lugar na terapêutica das psicopatologias, principalmente aliadas a uma psicoterapia em casos de sofrimento intenso. Discutem-se, neste texto, as promessas de bem-estar e felicidade "oferecidas" pela mídia e a medicalização da dor-de-existir. Questiona-se a tomada de uma posição subjetiva em que se busca desesperadamente uma felicidade plena, mesmo que plástica e artificial. O problema é o homem contemporâneo não aceitar mais os chamados "altos e baixos da vida" e querer estar apenas no "alto", o que faz com que muitas pessoas se considerem "anormais" por não compartilharem desse entusiasmo esfuziante.

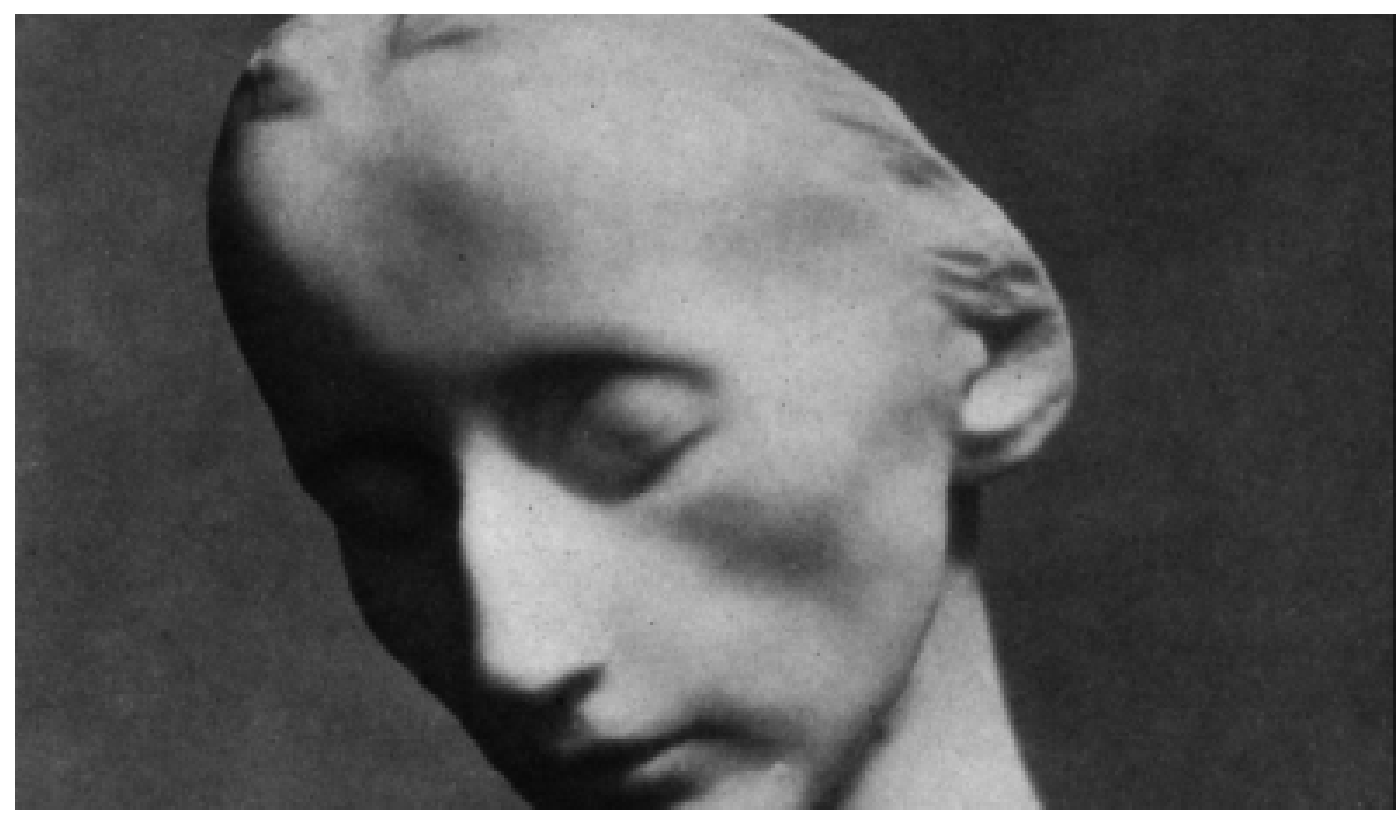


Birman, J. (1999). Mal-estar na atualidade. A psicanálise e as novas formas de subjetivação. Rio de Janeiro: Civilização Brasileira.

Bogochvol, A. (1997). Algumas reflexões sobre a psiquiatria biológica Em: Pulsional Revista de Psicanálise. Ano X, no. 99.

Calligaris, C. (2000). Deprimentes antidepressivos. Em: Pulsional Revista de Psicanálise. Ano XIII, no. 13

Freud, S. (1930[1929]) "O mal-estar na civilização" ESB, vol. XXI
Maia, M. \& Albuquerque, A. (2000). Get there now! Cultura contemporânea, imediatismo e desamparo. Pulsional: revista de psicanálise. AnoXIII, no. 132, 81-88.

Martins, F. (1995). Psicopatologia II. Semiologia psicanalítica: O sintoma simbólico. Brasília: Editora Universidade de Brasilia.

Scliar, M. (1997). Paraísos Artificiais. Em: Pulsional Revista de Psicanálise. Ano X, no. 99.Palavras-chave: Medicamento psicotrópico, subjetividade, cultura.
Referências

bibliográficas 